\title{
EL ARTE DE LA GUERRA APLICADO AL DEPORTE DE COMPETICIÓN
}

\author{
THE ART OF WAR APPLIED TO COMPETITIVE SPORTS
}

\author{
Gloria González-Campos ${ }^{1}$ \\ ${ }^{1}$ Facultad de Ciencias de la Educación, Universidad de Sevilla (España)
}

\section{Detalles del artículo:}

Número de palabras: 6.062; Tablas: 0; Figuras: 0; Referencias: 1

Recibido: enero 2019; Aceptado: enero 2019; Publicado: enero 2019

Conflicto de interés: El autor declara que no existen conflictos de interés.

Correspondencia del autor: Gloria González Campos, gloriagc@us.es

\section{Resumen}

Este artículo es una adaptación de la interesante y peculiar obra maestra clásica "El arte de la guerra" de Sun Tzu (2005) al deporte de competición de alto nivel. Concretamente en deportes colectivos. El autor nos enseña la estrategia para aplicar con sabiduría el conocimiento de la naturaleza humana en los momentos de confrontación. Es un tratado estratégico que extrapolado a los terrenos de juego, ofrece un paradigma único de superación y esfuerzo. Resulta ser un manual aconsejable para la figura del entrenador deportivo. El objetivo de este artículo es presentar la relación existente entre los elementos intervinientes en las batallas de la guerra y en las batallas deportivas, de manera que se transfieren los ingredientes de la guerra al deporte, y desde una perspectiva psicológica, aporta una forma de ver la competición, de afrontar retos, de rendir al máximo nivel, de intentar ganar..., de alcanzar la victoria. Los contenidos indispensables para lograr los objetivos en el deporte se basan en los aspectos que Sun Tzu recoge en su tratado militar: criterios estratégicos; en la batalla; la planificación; el orden; la fuerza; vacío y lleno; la lucha; las variables; maniobras; el terreno; las nueve clases de partidos; la provisión de información; el ataque. Las conclusiones a las que se llega en esta adaptación son, entre otras, que el entrenador debe afianzar su autoridad y marcar una línea disciplinaria, lo cual significa, organización, cadena de mando y logística. Además, seleccionar al valiente para que ataque, al cuidadoso para que defienda y al inteligente para que comunique. La pericia en la alineación determinará la fuerza del equipo. Asimismo, el entrenador debe proveerse de información para la planificación y la 
organización de un buen equipo, para que finalmente sepa que no basta saber cómo atacar, sino que es necesario saber cómo impedir que los demás te ataquen.

Palabras claves: deporte de alto nivel, deportes colectivos, estrategias militares, deportivas, variables psicológicas.

\section{Abstract}

This article is an adaptation of the interesting and peculiar classic masterpiece "The Art of War" by Sun Tzu (2005) to high level competitive sport. Specifically in collective sports. The author teaches us the strategie to wisely apply knowledge of human nature in moments of confrontation. It is a strategic treaty that extrapolated to the playing fields, offers a unique paradigm of overcoming and effort. It turns out to be an advisable manual for the figure of the sports trainer. The objective of this article is to present the relationship between the elements involved in the battles of war and sports battles, so that the ingredients of war are transferred to sport, and from a psychological perspective, it provides a way of seeing competition, to face challenges, to perform at the highest level, to try to win ..., to achieve victory. The essential contents to achieve the objectives in the sport are based on the aspects that Sun Tzu gathers in his military treaty: strategic criteria; in the battle; the planning; the order; the force; empty and full; the fight; variables; maneuvers; the land; the nine kinds of parties; the provision of information; the attack. The conclusions reached in this adaptation are, among others, that the coach must strengthen his authority and mark a disciplinary line, which means, organization, chain of command and logistics. Also, select the brave to attack, the careful to defend and the intelligent to communicate. The expertise in the lineup will determine the strength of the team. Also, the coach must provide information for the planning and organization of a good team, so that he finally knows that it is not enough to know how to attack, but it is necessary to know how to prevent others from attacking you.

Key words: high level sport, collective sports, military and sports strategies, psychological variables.

\section{INTRODUCCIÓN}

El desarrollo deportivo en la alta competición solicita una preparación física, técnicotáctica y psicológica llevada a su máximo nivel. Los agentes principales expuestos en el 
escenario de la competición, jugadores y entrenador, precisarán de los recursos necesarios para afrontar con éxito las demandas deportivas.

Se presenta este artículo basado en la interesante y peculiar obra maestra clásica "El arte de la guerra" de Sun Tzu, cuyo autor, nos enseña la estrategia suprema de aplicar con sabiduría el conocimiento de la naturaleza humana en los momentos de confrontación.

Es un tratado estratégico que extrapolado a los terrenos de juego, ofrece un paradigma único de superación y esfuerzo. Resulta ser un manual indispensable para la figura del entrenador deportivo. En él, una de sus sentencias aconseja "es mejor ganar sin lucha", distinguiendo así el hombre preparado del ignorante.

Realmente, cuando un equipo está perfectamente preparado en todos los aspectos que requiere el deporte, no le es necesario ganar sufriendo ni sentirse amenazado. Y esto se debe a que los jugadores conocen de manera bien definida sus posiciones y sus tareas, dominando así la situación. Pero no nos engañemos, en el terreno de juego, la lucha forma parte intrínseca del deporte, y es algo que todo jugador debe tener siempre muy presente. Lo que en realidad quiere decir esta máxima es: "si eres superior, demuéstralo fácilmente, si no es así, lucha hasta la extenuación".

El objetivo es la invencibilidad y, si es posible, la victoria sin batalla

La Estrategia principal ante las confrontaciones se basa en:

- Reconocer que cuanto menos se necesita algo o a alguien, mejor.

- Tratar la ausencia de armonía.

- El conocimiento de los problemas es la clave de la solución.

Esta estrategia taoísta nos muestra el camino de los antiguos maestros cuando decían: "el hombre violento y agresivo parece implacable, pero en realidad es una persona emocional".

El objetivo de este artículo es presentar la relación existente entre los elementos intervinientes en las batallas de la guerra y en las batallas deportivas, de manera que dicha relación consista en extrapolar los ingredientes de la guerra al deporte, y desde una perspectiva psicológica, aportar una forma de ver la competición, de afrontar los retos, de rendir,...de intentar ganar. 


\section{CONTENIDOS A TRABAJAR PARA GANAR EN EL DEPORTE}

En el deporte es necesario demostrar la implacabilidad, la frialdad de la objetividad total y a veces, la ausencia de benevolencia. Sólo así, el mejor deportista podrá expulsar fuera de sí, la codicia y la posesividad.

Los contenidos indispensables para lograr los objetivos en el deporte se basan en los siguientes aspectos: criterios estratégicos; en la batalla; la planificación; el orden; la fuerza; vacío y lleno; la lucha; las variables; maniobras; el terreno; las nueve clases de partidos; la provisión de información; el ataque.

\section{Criterios estratégicos}

En la acción deportiva es indispensable examinar cinco elementos, pues si ganas ventaja, vencerás y si la pierdes, perderás. Así de sencillo. Los cinco elementos son:

- El camino: significa inducir al equipo a tener el mismo objetivo que el entrenador para que puedan compartir las satisfacciones y las adversidades sin temores.

- El clima: tener muy claro que todos los integrantes del equipo deben estar predispuestos a una adaptación total en situaciones de frío, lluvia, altas temperaturas, cambios estacionales, altitud, etc.

- El terreno: previamente debe ser valorado en términos de dimensiones, seguridad, facilidad o dificultad de desplazamientos, etc.

- La autoridad: la figura del entrenador es considerada como extraordinariamente relevante. Este se debe caracterizar por: inteligencia, que implica capacidad de planificación y saber cuándo hay que hacer cambios oportunos; honradez, que significa que todo el equipo tenga claridad respecto a las recompensas y castigos; humanidad, demostrada teniendo conciencia ante los esfuerzos; valor, aprovechando sin vacilar las oportunidades para asegurar la victoria; severidad, estableciendo la disciplina mediante las correspondientes penalizaciones, que deben ser establecidas de antemano y, en consecuencia, siempre cumplidas.

- La disciplina: significa organización, cadena de mando y logística. La organización supone que el equipo debe estar agrupado de una determinada manera. La cadena de mando significa que debe haber capitán y mandos intermedios para mantener la unidad. La logística quiere decir, vigilancia de todos los elementos componentes.

El jugador debe saber que "el que lo amenaza de buena forma es su jefe, el que lo amenaza de manera cruel, es su enemigo"... 
Estar al mando de un grupo requiere capacidad para suscitar confianza, pero además debe contar con la capacidad de:

- Sorprender: incitar a sus jugadores a golpear los puntos flacos del contrario, atacar cuando estén descuidados, no permitirles que se preparen. "El movimiento más eficaz es aquel que no se espera, el mejor de los planes es el que no se conoce".

- Planificación: el que planifica la victoria previamente, es el que tiene más factores estratégicos de su parte. El que prevé su incapacidad para ganar es el que tiene menos factores estratégicos de su parte. El que tiene más factores estratégicos a su favor es el que gana. El que tiene menos factores estratégicos a su favor, pierde. Así se puede ver quién va a ganar y quién va a perder.

- Estrategia: cuando la estrategia es profunda y amplia, es mucho lo que llevas ganado mediante cálculos, de manera que puedes ganar incluso antes de empezar a luchar. Por eso se dice que "los guerreros victoriosos vencen primero y después van a la guerra, mientras que los guerreros vencidos van primero a la guerra $y$ después intentan vencer".

\section{En la batalla}

Es importante saber economizar energía, dosificándola o temporizándola. Sun Tzu dice que "los que disfrutan luchando y agotando sus fuerzas (...) morirán inevitablemente". Esto quiere decir que el gran deportista debe ser rápido y veloz desde que sale al terreno de juego, asfixiando al contrario, de manera que le deje claro que no tiene ninguna oportunidad, poniendo distancia en el marcador cuanto antes, pues nunca es beneficioso que el adversario piense que puede existir igualdad.

El grado de superación en una contienda debe ser cada vez mayor. El jugador debe pensar que "donde hay grandes recompensas, hay hombres valientes". La motivación debe permanecer constante, pues se mantiene a través del intento de consecución de los objetivos marcados y del aumento de la autoestima como alguien importante.

El entrenador debe ser muy hábil, pues si recompensa siempre a todo el mundo, aparte de que puede que no haya suficiente para todos, no se le presta el valor que merece. Así pues, debe ofrecer recompensas a algunos para animar a todos los demás. Obviamente hablamos de una táctica psicológica.

En la batalla, "si utilizas al enemigo para derrotar al enemigo, serás poderoso en cualquier lugar que vayas”. Quiere decir, preocúpate por conocer bien a tu adversario, así sabrás sus puntos vulnerables $\mathrm{y}$, apoyándote en ellos, derrotarlo poderosamente. En la 
competición, lo que finalmente suele importar, al igual que en la guerra, es la victoria. Si en algún momento hay que utilizar el engaño sería la peor táctica a emplear, por lo tanto habrá que utilizar absolutamente todas las armas disponibles para alcanzar esa victoria.

\section{La planificación}

"Calcula la fuerza de tus adversarios, haz que pierdan su ánimo y dirección, de manera que sean inservibles". Los que consiguen que sus adversarios se rindan impotentes son los mejores maestros del arte del deporte.

No se debe atacar bajo la ira y con prisas, siempre se aconseja tomarse tiempo. También es importante llegar hasta el final, obtener una victoria completa para que el beneficio sea total.

"Si tus fuerzas son diez veces superiores a las del adversario, rodéalo; si son cinco veces superiores, atácalo; si son dos veces superiores, divídelo (desarma sus estrategias), si tus fuerzas son iguales en número, lucha; si son inferiores, lucha más”.

Si tus fuerzas, tus estrategias y tu valor son menores que las de tu adversario, entonces debes: entrenar más, intentar mejorar, superarte y si pierdes, acepta la derrota.

No se puede ser torpemente obstinado: "si no puedes ser fuerte, pero tampoco sabes ser débil, serás derrotado".

Como entrenador, tu planificación tiene que recoger aspectos fundamentales que influyen en el buen funcionamiento del equipo. Es imprescindible ser cuidadoso al elegir a las personas que van a tener puestos de responsabilidad en él.

Existen tres maneras en las que la dirección de un equipo deportivo lleva a este al desastre:

1. Inmovilizar al equipo, ignorando cuándo y cómo hay que llevar a cabo las tareas oportunas.

2. Confusión en el equipo. Los dirigentes van por caminos diferentes y existe ausencia de unidad direccional.

3. Jugadores vacilantes. Falta de credibilidad o confianza en los dirigentes.

Si se utilizan métodos estrictamente directivos para dirigir acciones deportivas, las operaciones serán confusas.

Finalmente, es importante saber que existen cinco maneras de conocer al futuro vencedor. Ganan los que:

- Saben cuándo luchar y cuándo no. 
- Los que saben discernir cuándo utilizar muchas o pocas armas.

- Los que teniendo un rol u otro en el equipo, tienen el mismo propósito.

- Los que se enfrentan con preparativos a contrincantes desprevenidos.

- Los que tienen entrenadores competentes y no están limitados por dirigentes del club.

Por consiguiente, se dice que "si conoces a los demás y te conoces a ti mismo, ni en cien batallas correrás peligro; si no conoces a los demás, pero te conoces a ti mismo, perderás una batalla y ganarás otra; si no conoces a los demás ni te conoces a ti mismo, correrás peligro en cada batalla, raras veces ganarás".

\section{El orden}

Todo es una cuestión de orden, de cambiarlo o de mantenerlo. De ello dependerá el resultado. Así pues, si partimos de "hacernos a sí mismos invencibles en primer lugar, y después descubrir la vulnerabilidad de los adversarios", este orden abre el paso a reflexionar sobre la siguiente frase: "la invencibilidad es una cuestión de defensa, la vulnerabilidad, es cuestión de ataque". Esto quiere decir que somos invencibles porque conocemos a la perfección cómo defendernos, y podemos ser vulnerables porque no sabemos atacar eficazmente. Pero, ¿y si cambiamos el orden?, el resultado sería: somos invencibles porque sabemos atacar eficazmente y podemos ser vulnerables porque no conocemos a la perfección cómo defendernos. En este caso la frase quedaría: "la invencibilidad es una cuestión de ataque, la vulnerabilidad, es cuestión de defensa".

¿Con cuál te quedas? ¿Cuál se identifica contigo? ¿En cuál crees?

No obstante, en la guerra, se piensa que "la defensa es para tiempos de escasez, el ataque para tiempos de abundancia”. En el deporte, hay equipos que también lo ponen en práctica.

Para lograr la victoria segura, no existe más que tener expertos en defensa y expertos en ataque. En situaciones de defensa hay que mostrarse invisible y en situaciones de ataque se necesitan movimientos rápidos y veloces, para que el contrario no se pueda preparar.

Todo el mundo elogia la victoria en el deporte pero lo verdaderamente interesante es “poder ver el mundo de los sutil y darse cuenta del mundo de lo oculto".

En consecuencia, "las victorias de los buenos guerreros no destacan por su inteligencia o su bravura. Asimismo, las victorias que se ganan en batalla no son debidas a la suerte. Sus victorias no son casualidades, sino que son debidas a haberse situado previamente en posición de poder ganar con seguridad, imponiéndose sobre los que ya han perdido de antemano". 
La gran sabiduría no es algo obvio, el mérito grande no se anuncia. Cuando eres capaz de ver lo sutil, es fácil ganar. Cuando se resuelven los problemas antes de que surjan, eso es actuar inteligentemente, aunque no se le suela llamar así. Cuando hay victoria sin batalla, posiblemente se deba a que el adversario teme nuestra bravura, aunque se suela decir que no la hubo.

Los buenos jugadores toman posición en un terreno en el que no pueden perder, y no pasan por alto las condiciones que hacen a su adversario proclive a la derrota.

"Un ejército victorioso gana primero y entabla la batalla después; un ejército derrotado lucha primero e intenta obtener la victoria después". Esta es la diferencia entre los que tienen estrategia y los que no la tienen. En el deporte, exactamente igual, el jugador victorioso, tiene en su mente que va a ganar y luego hace lo que tiene que hacer para lograrlo. Sin complacencia.

\section{La fuerza}

$\mathrm{Si}$ abrimos la ventana de la técnica, táctica y estrategia, encontramos que "gobernar sobre muchas personas como si fueran pocas es una cuestión de dividirlas en grupos. Batallar contra un gran número de tropas como si fueran pocas es una cuestión de despliegue y de señales". Combatir sin ser derrotado es una cuestión de emplear métodos ortodoxos y métodos heterodoxos, atacar inesperadamente, volviéndose así inescrutable para el enemigo. Por lo tanto, podemos entender que el contraataque es un arma casi mortífera para un adversario. Lo importante es saberlo propiciar. Esto sería un contraataque apoyándonos en la fuerza. "Cuando induces a los adversarios a venir a ti, su fuerza siempre está vacía; mientras que no vayas hacia ellos, tu fuerza siempre está llena. Atacar el vacío con el lleno es como arrojar piedras sobre huevos: es seguro que éstos se rompen”.

La fuerza se representa de muchas formas. Es importante "saber ser" para aparentar lo contrario. Por ejemplo, “el desorden llega del orden, la cobardía surge del valor, la debilidad brota de la fuerza". Quiere decir que si pretendes fingir desorden para conducir a tus adversarios al mismo, primero tienes que completar el orden, porque sólo entonces puedes crear un desorden artificial. Si quieres fingir cobardía para espiar a los adversarios, primero tienes que ser extremadamente valiente, porque sólo entonces puedes actuar como tímido de manera artificial. Si quieres fingir debilidad para inducir la arrogancia en tus enemigos, primero has de ser extremadamente fuerte, porque sólo entonces puedes fingir ser débil. Así pues, el orden y el desorden son una cuestión de organización. La valentía y la cobardía son una cuestión de ímpetu. La fuerza y la debilidad son una cuestión de formación del equipo. 
Cuando un equipo tiene la fuerza del ímpetu, incluso el temeroso se vuelve valiente; cuando pierde la fuerza del ímpetu, incluso el valiente se convierte en cobarde. Nada está fijado en las leyes del arte del deporte, estas se desarrollan sobre la base del ímpetu.

Un entrenador experto hace que su equipo provoque al contrario para moverse estableciendo un orden determinado, así el adversario va a seguir dicho orden. Les dan lo que estos están seguros que van a tomar. "Hacen moverse a los enemigos con la perspectiva del triunfo, esperando que caigan en la emboscada".

El entrenador debe saber que es posible escoger a sus jugadores por sus capacidades y darles las responsabilidades adecuadas. El valiente puede atacar, el cuidadoso puede defender y el inteligente puede comunicar. Nadie es inútil.

Cuando uno conduce a su equipo a la batalla con pericia, el impulso es como rocas redondas que se precipitan montaña abajo, esta es la fuerza

\section{Vacío y lleno}

Para establecer un buen dominio técnico-táctico en el deporte, los buenos jugadores hacen que los demás vengan a ellos, y de ningún modo se dejan atraer fuera de algo que ellos desconozcan. Por lo tanto, si haces que los adversarios vengan a ti para combatir, su fuerza se vaciará, de manera que tu fuerza estará llena. Esto es algo que hay que saber conjugar. Es lo que se llama el arte de vaciar a los demás para llenarte a ti mismo.

Para sorprender hay que atacar inesperadamente, haciendo que los adversarios se agoten corriendo y cortar sus vías de aprovisionamiento. Aparecer en lugares críticos y atacar donde menos se lo esperen.

Para tomar infaliblemente lo que atacas, ataca donde no hay defensa. Para mantener una defensa infaliblemente segura, defiende (incluso) donde no haya ataque

Además, para sorprender no hay nada como la eficacia de la discreción. "Sé extremadamente sutil, hasta el punto de no tener forma. Sé completamente misterioso, hasta el punto de ser silencioso. De este modo podrás dirigir el destino de tus adversarios". Luego actúa con decisión y Asertividad. Las situaciones competitivas se basan en la velocidad: “llega como el viento, parte como el relámpago, y los adversarios no podrán vencerte”. Si el 
contrario está atrincherado en una posición defensiva, no podrá evitar luchar si atacas adecuadamente.

En el contrincante hay que crear expectativas de impotencia: "Haz que los adversarios vean como extraordinario lo que es ordinario para ti; haz que vean como ordinario lo que es extraordinario para ti”. De esta manera, la autoconfianza juega un papel fundamental en el jugador: "Cuando estás preparado y te has hecho fuerte, sal, ataca y conquista de manera insondable". Cuantas más defensas induces a adoptar a tu contrario, más debilitado quedará.

Obligando a tu adversario a defender, poco atacará

Un entrenador siempre debe tener presente que se requiere hacer un estudio previo del contrario. Hacer una valoración para averiguar sus planes, descubrir sus hábitos de ataque y defensa. Utilizar métodos para saber qué situaciones significan ganar y cuáles significan perder. Averiguar sus puntos fuertes y sus puntos débiles. Luego se debe llevar a cabo una adaptación según ese contrario. Determinar los cambios apropiados significa no repetir las estrategias previas para obtener la victoria. Para lograrla, puede adaptar su equipo desde el principio a cualquier formación que los adversarios puedan adoptar. Se llama genio a la capacidad de obtener la victoria cambiando y adaptándose según el contrario.

\section{La lucha}

Una labor insoslayable del entrenador es unificar los oídos y los ojos de los jugadores, pues esto significa hacer que miren y escuchen al unísono de manera que no caigan en la confusión y el desorden. Las señales se utilizan para indicar direcciones e impedir que vayan a donde se les antoje.

En lo que respecta al jugador, utiliza señales para comunicarte con tus compañeros de grupo, y durante la lucha, resulta fundamental el control emocional. En primer lugar, has de ser capaz de mantenerte firme en tu propio corazón. "Utilizar el orden para enfrentarse al desorden, utilizar la calma para enfrentarse a lo que te pueda agitar, esto es dominar el corazón”. Aquí es donde recae la lucha del jugador por encontrar su estabilidad mental.

Si tu corazón está abierto y tu mente en orden, puedes responder sin límites enfrentándote a dificultades inesperadas sin tumbarte, dirigiendo cada cosa sin confusión 


\section{Las variables}

"Cuando te halles en un partido difícil, discurre alguna estratagema. Cuando te halles en un partido perdiendo, lucha". Cansa a los contrarios manteniéndolos ocupados y no dejándoles respiro. Esa labor consiste en desarrollar un fuerte equipo, con recursos, un grupo armonioso y una manera ordenada de vivir.

La Anticipación se considera una acción genial de los jugadores en el desarrollo de un encuentro, pues bien, si puedes recordar el perder cuando vas ganando y recordar el caos en situaciones de orden, permanece atento a los posibles errores mientras no tengan todavía forma, y evítalos antes de que se presenten. Esta es sin duda, la mejor estrategia de todas.

Existen cincos rasgos que son peligrosos en los deportistas:

1. Los que están dispuestos a la entrega sin controlar los aspectos relevantes de un encuentro $\rightarrow$ pueden perder el partido.

2. Los que juegan a no perder $\rightarrow$ pueden ser vapuleados.

3. Los que no se controlan emocionalmente $\rightarrow$ pueden ser ridiculizados.

4. Los que temen a la confrontación, a las lesiones, al choque $\rightarrow$ pueden ser desahuciados.

5. Los que se apiadan del contrario $\rightarrow$ pueden ser barridos.

Estos cinco rasgos que constituyen defectos, pueden ser desastrosos en el desarrollo de un partido. Los buenos jugadores se comprometen hasta la muerte, pero controlando todos los aspectos del juego, actúan de acuerdo con los acontecimientos sin ser proclives a la ira ni estar sujetos a quedar confundidos. Cuando ven la posibilidad, son como tigres, su acción y su no acción son cuestiones de estrategia. Por eso no pueden ser complacidos ni enfadados por sus adversarios, pues en ambos casos los atacaría duramente.

\section{Maniobras}

En este apartado es imprescindible considerar el entrenamiento invisible (el cuidado de la alimentación, el descanso y la higiene). Cuando en un equipo se cuida la salud física y no existen enfermedades ni lesiones, se dice que puede ser invencible. Aunque se necesita un compendio de múltiples factores para consolidar este aforismo, no cabe duda que puede ser la base del desarrollo óptimo de un equipo fuerte, duro y rápido. Según sean las maniobras que se realicen en el equipo, así se manifestará.

Vamos a considerar determinados síntomas para sospechar qué puede estar ocurriendo en un equipo deportivo: 
- Si el contrario ve una ventaja pero no intenta aprovecharla, puede ser que esté cansado.

- Si el equipo no tiene disciplina, quiere decir que el entrenador no es tomado en serio.

- Si un conjunto de jugadores muestra irritación, también puede significar que estén cansados.

- Si se producen murmuraciones, faltas de disciplina y los jugadores hablan mucho entre sí, quiere decir que se puede estar perdiendo la lealtad, que hay desconcierto. En definitiva, puede haber desavenencias y críticas al entrenador.

Además, en un grupo de jugadores se suele dar que alguno no tenga un plan previo, sino que confíe exclusivamente en su coraje individual, y tome a la ligera a sus adversarios, así con toda seguridad, no logrará sus objetivos ni ayudará a su equipo.

Por otra parte, cuando existe en el deportista un sentimiento de confianza grande relajando la disciplina, se volverá arrogante y será imposible que se implique en la tarea.

"Cuando las órdenes se dan de manera consecuente para edificar a las tropas, estas las aceptan. Cuando las órdenes no son dadas de manera consecuente para edificar a las tropas, estas no las aceptan. Cuando las órdenes son justas, existe una satisfacción recíproca entre el líder y el grupo".

Por lo tanto, entrenador: ¡dirígelos y unifícalos!, así significará casi una victoria segura. Mándalos con humanidad y benevolencia, unifícalos de manera estricta y firme. Cuando la benevolencia y la firmeza son evidentes, es posible estar seguro de la victoria.

\section{El terreno}

Algunos terrenos son fácilmente adaptables para jugar, otros son difíciles, algunos son neutros, otros son estrechos, accidentados o abiertos.

Cuando el terreno sea fácilmente accesible, sé el primero en establecer tu juego. Cuando es un terreno desfavorable para ambos equipos, se dice que es un terreno neutro. Sé precavido, y atento a que él también cometerá errores. Según las configuraciones del terreno, los entrenadores que las ignoran salen derrotados.

Así pues, entre los equipos, están los que huyen, los que se retraen, los que se derrumban, los que se rebelan y los que son derrotados. Estos, en muchos de los casos son debidos a los fallos de los entrenadores respecto a previsiones de características del terreno de juego. 
Pero también existen diferentes formas de ser derrotado por irresponsabilidad suprema del entrenador, porque como norma general, para poder vencer al contrario, todo el equipo debe tener una sola intención y todos deben cooperar. Cuando los dirigentes son débiles y carecen de autoridad, cuando las órdenes no son claras, cuando nadie tiene solidez y las formaciones son anárquicas, se produce la revuelta.

Los entrenadores que son derrotados son aquellos que son incapaces de calibrar a los adversarios, y no seleccionan a sus jugadores según los niveles de preparación de sus cualidades, por lo que los errores serían:

- No calibrar el número de fuerzas contrarias.

- La ausencia de un sistema claro de recompensas y castigos.

- La insuficiencia de entrenamiento.

- La pasión irracional.

- La ineficacia del orden.

- El fallo de no seleccionar a los jugadores fuertes y resueltos.

El dominio de un terreno de juego puede ser un apoyo para un equipo. Para los entrenadores, la acción adecuada es calibrar al adversario para asegurar la victoria y calcular los espacios y las distancias. Salen vencedores los que conocen estos elementos. Salen derrotados los que luchan ignorándolos.

Mira por tus jugadores como miras por un recién nacido; así estarán dispuestos a seguirte en todos los pasos; cuida de tus deportistas como cuidas de tus bienamados hijos, y seguirán trabajando gustosamente contigo.

Pero si eres tan amable con ellos que no los puedes utilizar. Si eres tan indulgente que no les puedes dar órdenes. Tan informal que no puedes disciplinarlos, tus jugadores serán niños mimados y por lo tanto, inservibles

\section{Las nueve clases de partidos}

Existen nueve clases de partidos:

1. Partido de dispersión: cuando no existe armonía en el propio equipo. Los jugadores se dispersan con facilidad.

2. Partido fronterizo: cuando se disputa en un campo desconocido y no se juega en profundidad. Los jugadores se rinden fácilmente. No se ataca.

3. Partido de disputa: puede ser ventajoso si uno toma las riendas del encuentro, y ventajoso para el contrario si es él quien las toma. Es un partido igualado en fuerzas. 
4. Partido de comunicación: los dos equipos se mantienen conservando y ninguno toma la iniciativa en ataque.

5. Partido de intersección: se trata de un encuentro duro y difícil, pero el primero que marca, gana.

6. Partido difícil: cuando se arriesga tras la necesidad de ganar y se ataca sin cubrir totalmente el contraataque.

7. Partido desfavorable: cuando se dan todas las adversidades de superficie, clima, ambiente,... para un equipo.

8. Partido cercado: cuando a pesar de tener bien controlado todos los aspectos del propio equipo, existe un gran peligro por parte del contrario.

9. Partido mortal: cuando por todos los medios hay que intentar ganar, luchando al máximo y con rapidez, pero lo más fácil es perder, pues el contrario es muy, muy superior.

No obstante, las pautas a seguir en cualquier partido para obtener la victoria son: jugar con rapidez de acción que determina la condición de la fuerza de un equipo, aprovecharse de los errores de los adversarios, desplazarse por donde el contrario no lo espera y atacar fundamentalmente cuando no están preparados.

"Un equipo preparado con pericia debe ser como una serpiente veloz que contraataca con su cola cuando alguien le ataca por la cabeza, contraataca con la cabeza cuando alguien le ataca por la cola, y contraataca con cabeza y cola cuando alguien le ataca por sus anillos".

Puede plantearse la cuestión de si es posible hacer que un equipo sea como una serpiente rápida. La respuesta es afirmativa. Incluso los jugadores que por algún motivo no congenian entre sí, perteneciendo a un mismo equipo, se ayudarán en el terreno de juego. Es la fuerza de la situación la que hace que esto suceda. Es necesario que luchen de forma espontánea y se ayuden unos a otros codo con codo: este es el camino de la seguridad y de la obtención de una victoria cierta. Esto corresponde a la labor del entrenador, mediante su comportamiento tranquilo, reservado, justo y metódico.

Cuando el mando de un entrenador es justo y metódico, nadie se atreve a tomarlo a la ligera

Es función del entrenador colocar a sus jugadores en situaciones de partido en los entrenamientos. También ha de examinar las adaptaciones a los diferentes terrenos, las 
ventajas de atacar o defender en cada momento, y las pautas a seguir respecto a los sentimientos y situaciones humanas que en un equipo se produzcan.

Conocer a los adversarios, aprovecharse del terreno, llevar al contrario de manera que se encuentre indefenso, y sobre todo, como factor imprescindible para romper la rutina del acontecer diario, sorprender y captar la atención de sus jugadores. Esto último se consigue otorgando recompensas que no estén reguladas y dando órdenes desacostumbradas.

\section{La provisión de información}

Otro de los factores importantes que posibilita vencer a los demás y lograr triunfos extraordinarios es la información previa, tanto de los adversarios como sobre los posibles fichajes futuros que se pueden hacer para reforzar o mejorar un equipo.

La información previa no puede obtenerse mediante cálculos. Debe conseguirse a través de personas que se muevan y conozcan perfectamente la situación del adversario, o en el caso de fichar refuerzos, las características de estos de manera contrastada.

A todo esto se le llama genio organizativo. Pues la búsqueda de información es esencial para la planificación y la organización de un buen equipo.

\section{El ataque}

Simplemente, teniendo muy claro todo lo concerniente al complejo concepto técnicotáctico que requiere el deporte de competición, podemos asegurar que "no basta saber cómo atacar, es necesario saber cómo impedir que los demás te ataquen a ti”.

Todos estos factores que intervienen en el deporte de competición que se identifican con las características que despliega el "Arte de la Guerra" desembocan en otra de las célebres frases del maestro Sun Tzu:

Cuando te conoces a ti mismo y conoces a los demás, la victoria no corre peligro. Cuando conoces el cielo y la tierra, la victoria es inagotable

\section{CONCLUSIONES}

Esta aportación maestra de Sun Tzu, aplicada al deporte de equipo de alto nivel, determina que los entrenadores que ostenten alcanzar el alto grado de liderazgo y lograr el éxito deportivo, deben cumplir con las máximas siguientes:

- Seguir unos criterios estratégicos, entre ellos, afianzar su autoridad y marcar una línea disciplinaria, lo cual significa, organización, cadena de mando y logística. 
- En la batalla, la motivación debe permanecer constante intentando conseguir los objetivos marcados, por lo que las recompensas del entrenador deben alcanzar el valor que merecen, respaldando aquí su habilidad para otorgarlas.

- La planificación tiene que recoger aspectos fundamentales que influyan en el buen funcionamiento del equipo. Es imprescindible ser cuidadoso al elegir a las personas que van a tener puestos de responsabilidad en él.

- Un equipo victorioso gana primero y entabla la batalla después, ya que tiene en su mente que va a ganar y luego, hace lo que tiene que hacer para lograrlo sin complacencia. Este es el orden de los pensamientos que el entrenador debe hacer que el jugador albergue en su mente.

- La fuerza de un equipo se consolida con la habilidad del entrenador en la configuración del mismo. Seleccionar al valiente para que ataque, al cuidadoso para que defienda y al inteligente para que comunique. La pericia en la alineación determinará la fuerza del equipo.

- Jugar con el vacío y lleno significa que los buenos jugadores hacen que los demás vengan a ellos, y nunca se dejan atraer fuera de algo que ellos desconozcan. Si haces que los adversarios vengan a ti para combatir, su fuerza se vaciará, de manera que tu fuerza estará llena. Esto es algo que hay que saber conjugar. Es lo que se llama el arte de vaciar a los demás para llenarte a ti mismo.

- La lucha se halla en tu interior con el objetivo de controlar las emociones para mantener tu mente firme y en orden. Lograr la estabilidad mental en los momentos difíciles es la gran batalla que hay que liderar.

- Hay variables a considerar como la anticipación a cuidar los detalles para que los errores no alcancen su forma. Para ello, el jugador debe controlar sus movimientos, sus emociones y sus temores. Todo esto hay que entrenarlo.

- Según se desarrollen las maniobras en un equipo, así se manifestará este. Cuando las órdenes son justas, existe una satisfacción recíproca entre el líder y el grupo. Si la benevolencia y la firmeza son evidentes, es posible estar seguro de la victoria.

- El terreno de juego supone un factor importante a tener en cuenta. Algunos son fácilmente adaptables para jugar, otros son difíciles, algunos son neutros, otros son estrechos, accidentados o abiertos. Los entrenadores que ignoran su configuración, salen derrotados.

- Existen nueve clases de partidos: de dispersión, fronterizo, de disputa, de comunicación, de intersección, difícil, desfavorable, cercado, o mortal. Según el 
conocimiento del entrenador de sus adversarios, del terreno y de captar la atención de sus jugadores, así será el partido.

- La provisión de información es esencial para la planificación y la organización de un buen equipo. Es lo que se denomina genio organizativo.

- En cuanto al ataque, no basta saber cómo atacar, es necesario saber cómo impedir que los demás te ataquen a ti. Todo basado en el conocimiento, pues cuando te conoces a ti mismo y conoces a los demás, la victoria no corre peligro.

\section{Referencias}

Cleary, T. (2005). El arte de la guerra de Sun Tzu. Madrid: EDAF. 